\title{
Interventions for improving adherence to treatment for latent tuberculosis infection: a systematic review
}

\author{
Anke L. Stuurman ${ }^{1}$, Marije Vonk Noordegraaf-Schouten ${ }^{1}$, Femke van Kessel', Anouk M. Oordt-Speets ${ }^{1}$,
} Andreas Sandgren ${ }^{2}$ and Marieke J. van der Werf ${ }^{2 *}$

\begin{abstract}
Background: Latent tuberculosis infection (LTBI) control relies on high initiation and completion rates of preventive treatment to preclude progression to tuberculosis disease. Specific interventions may improve initiation and completion rates. The objective was to systematically review data on determinants of initiation, adherence and completion of LTBI treatment, and on interventions to improve initiation and completion.

Methods: A systematic review of the literature (PubMed, Embase) published up to February 2014 was performed. Relevant prospective intervention studies were assessed using GRADE.

Results: Sixty-two articles reporting on determinants of treatment initiation and completion were included and 23 articles on interventions. Determinants of LTBI treatment completion include shorter treatment regimen and directly observed treatment (DOT, positive association), adverse events and alcohol use (negative association), and specific populations with LTBI (both positive and negative associations). A positive effect on completion was noted in intervention studies that used short regimens and social interventions; mixed results were found for intervention studies that used DOT or incentives.

Conclusion: LTBI treatment completion can be improved by using shorter regimens and social interventions. Specific needs of the different populations with LTBI should be addressed taking into consideration the setting and condition in which the LTBI treatment programme is implemented.
\end{abstract}

Keywords: Tuberculosis, Latent tuberculosis, Treatment initiation, Treatment adherence, Treatment completion, Risk groups

\section{Background}

Exposure to Mycobacterium tuberculosis may result in latent tuberculosis infection (LTBI). LTBI can in turn progress to tuberculosis (TB) disease, especially if the immune system is compromised $[1,2]$. One-third of the world population is estimated to be latently infected with $M$. tuberculosis [3]; therefore, LTBI control is an important step towards TB elimination, in addition to $\mathrm{TB}$ case detection and treatment $[4,5]$. LTBI control consists of identifying individuals with LTBI and offering them preventive treatment. The fact that initiation and

\footnotetext{
*Correspondence: marieke.vanderwerf@ecdc.europa.eu

${ }^{2}$ European Centre for Disease Prevention and Control (ECDC),

Tomtebodavägen 11a, Solna 171 65, Sweden

Full list of author information is available at the end of the article
}

completion rates of preventive treatment are often low and differ between treatment regimens and populations with LTBI may hamper the control of LTBI.

Numerous factors can influence patients' medication uptake, such as forgetfulness, side effects, stigma, or lack of information on treatment requirements, thereby affecting initiation, adherence and completion rates of treatment. These factors affecting patients' medication uptake have to be considered when designing interventions to modify complex human behaviour associated with treatment adherence [6-8]. Specific examples of interventions that have been used to improve initiation, adherence, or completion of LTBI treatment include switching from regimens with longer treatment duration 
to regimens with shorter treatment duration [9], incentives [10], and education or counselling [7].

In order to provide European Union and European Economic Area (EU/EEA) Members States and candidate countries with guidance on programmatic LTBI control a systematic review on initiation and completion of preventive treatment was performed in a bilateral cooperation with the World Health Organization (WHO) [11]. The review served as input for the WHO guidelines on management of LTBI launched in 2015 [11], and will be used for the EU/EEA tailored guidance. The review questions were (1) What are the initiation and completion rates of different LTBI treatment regimens?; (2) What are the determinants of initiation, adherence, and completion of recommended LTBI treatment regimens in the general population and in specific populations with LTBI?; and (3) What are interventions with demonstrated efficacy to improve LTBI treatment initiation, adherence and completion in different populations?. The current article presents the results on the latter two review questions.

\section{Methods}

A systematic literature review was performed to provide answers to the review questions described above. This review was done according to a review protocol and following the Cochrane guidelines. The details of eligibility criteria, information sources, search strategy, study selection, and data extraction are provided in the Additional files (see Additional file 1).

\section{Data extraction}

To answer review question 2, data on determinants of initiation, adherence, and completion were extracted for individuals with LTBI from various populations with LTBI (e.g. p-values, odds ratios (ORs), risk ratios). If univariate and multivariate analyses of the same data were presented, only the data from the multivariate analysis were extracted. Results from intention-to-treat analyses were preferred; if both intention-to-treat and per-protocol results were reported in one study, only intention-to-treat results were included. Data on non-significant factors were not consistently quantified in the studies and were therefore not listed in this review.

For review question 3, data for five groups of interventions were extracted: 1 . interventions with short treatment regimens; 2. interventions consisting of directly observed therapy (DOT); 3. interventions in which incentives were offered with the treatment (e.g. cash, transportation vouchers); 4. social interventions (e.g. education, adherence coaching, peer counselling, cultural interventions); and 5. other interventions (e.g. use of interferon gamma release assay (IGRAs) rather than tuberculin skin tests (TSTs)). ORs that were adjusted for factors that related to the intervention were not used.

\section{GRADE}

As review question 2 does not deal with the effects of health interventions, risk of bias was only assessed for aspects of the individual studies and not across the evidence base. For review question 3, the quality of the total body of evidence for each outcome (initiation, adherence, and completion rates) was critically appraised using the GRADE approach (Grading of Recommendations Assessment, Development and Evaluation; http://www.gradeworkinggroup.org). Only prospective studies (i.e. randomized controlled trials (RCTs) and prospective observational studies) were appraised using GRADE. Outcomes were downgraded for imprecision when the total number of events was less than 125 for dichotomous outcomes, and if the total sample size was less than 230 for continuous outcomes (based on estimated control group event rate of 0.60 and a relative risk difference of $30 \%$, given $\alpha=0.05$ and $\beta=0.20$ ) [12]. GRADE tables were created using standard GRADE formats and procedures (with GRADEpro [13]). Metaanalysis was performed in accordance with GRADE methodology: summary odds ratios (sORs) and $95 \%$ confidence intervals were calculated when the outcomes were considered relatively homogeneous regarding the intervention and the population. This was done using a random effects model with the "MAInput Table" and "MAPooledEffect" functions from the MetaXL 2.1 add-in in Excel. No quality index was used. The sORs and a measure for heterogeneity $\left(\mathrm{I}^{2}\right)$ are shown in a forest plot [14].

\section{Results}

\section{Results of the review process}

Results are reported in accordance with the Preferred Reporting Items for Systematic Reviews and Meta-Analyses (PRISMA) statement. A flowchart showing the number of articles identified for all review questions during the selection process is presented in in the Additional files (see Additional file 2).

Overall, 62 articles were found for review question 2, including 27 prospective studies and 35 retrospective studies (see Additional file 3). Twelve articles provided information on determinants of initiation, eight on determinants of adherence, and 51 on determinants of completion. Twenty-three articles were found for review question 3 , including twenty prospective and three retrospective studies (see Additional file 4). Among the prospective studies, seven articles described interventions with short treatment regimens, four with DOT, four with incentives, eight with social interventions, and one described another type of intervention. Four prospective studies provided data for more than one outcome [15-21]. 
Determinants of LTBI treatment initiation, adherence and completion

Most determinants of LTBI treatment initiation, adherence, and completion are from studies in the general population, i.e. primarily unselected patients with LTBI at clinics (Table 1). The most frequently reported determinant associated with LTBI treatment uptake in the general population was age, though the direction of the effect was inconsistent. Most determinants related to LTBI treatment completion.

With regards to LTBI treatment initiation, two studies found healthcare workers (vs. non healthcare workers) to be less likely to initiate treatment $[22,23]$ (no study found a positive association); three studies found case contacts (vs. no case contacts) [22-24], and two studies found immigrants or refugees (vs. born in country of study) $[25,26]$ to be more likely to initiate LTBI treatment (no study found an inverse association). With regards to LTBI treatment completion, five studies found a positive association between completion and immigrant or refugee status (vs. born in country of study) [27-31], whereas two studies found an inverse association [32, 33]. Two studies each found that currently homeless individuals [30, 32] (vs. not currently homeless) and people who injected drugs (PWID) [23, 34] (vs. people who do not inject drugs) were less likely to complete treatment (no study found a positive association). Throughout the populations, unfavourable social risk factors were associated with worse completion [23, 25, 27, 35-38] (no study found a positive association). Determinants of treatment initiation, adherence or completion within specific source populations with LTBI are presented in the Additional files (see Additional file 3), and showed large analogy with the determinants identified for the general population. Short (vs. long) treatment regimens and treatments with DOT (vs. self-administered therapy (SAT)) were found to be completed more often in the general population with LTBI in six [31, 39-43] and three $[31,44,45]$ studies, respectively, (no study found an inverse association). Adverse events were inversely associated with completion in seven studies [30, 33, 41, 46-49] (no study found a positive association). Similar results were found for determinants of completion in individuals from the different populations (see Additional file 3). Females [30, 44] (vs. males) were more likely to complete treatment (no study found men were more likely to complete treatment). Additionally, alcohol use (vs. no alcohol use) was inversely associated with completion in four studies [29, 30, 32, 49] (no study found a positive association).

\section{Interventions to improve LTBI treatment initiation,} adherence and completion

Twenty prospective studies on interventions to improve LTBI treatment initiation, adherence, and/or completion provided evidence for the following questions (Tables 2, 3, 4, 5, 6):

\section{Does short $L T B I$ treatment result in higher initiation, adherence, or completion rates than long LTBI treatment in individuals eligible for LTBI treatment (Table 2)?}

Case contacts showed better adherence when receiving short treatment (2 studies; sOR $=1.5 ; 95 \%$ CI 1.0-2.3; low heterogeneity, moderate quality of evidence) $[21,50]$ (Fig. 1). One of these studies also provided completion rates but found no association with shorter treatment duration $(\mathrm{OR}=0.8$; $95 \%$ CI $0.5-1.3$; moderate quality of evidence) [21]. All other studies found higher completion rates in the short treatment group: in immigrants with LTBI (1 study; OR = 2.5; $95 \%$ CI 1.7-3.6; moderate quality of evidence) [38], in the general population with LTBI ( 2 studies; sOR $=1.9$; $95 \%$ CI 1.1-3.5; large heterogeneity, moderate quality of evidence) [51-53] (Fig. 2), and in case contacts ( 1 study; OR $=2.1 ; 95 \%$ CI 1.9-2.3; low quality of evidence) [20]. The latter result is confounded, however, by the use of DOT in the short treatment group and SAT in the long treatment group.

\section{Does DOT result in higher initiation, adherence, or completion rates than SAT in individuals eligible for LTBI treatment (Table 3)?}

In undocumented migrants, significantly lower completion rates were found among those receiving twice weekly clinic-based DOT compared to daily SAT (OR $=0.1 ; 95 \%$ CI 0.0-0.3; low quality of evidence) [54] or twice weekly SAT $(\mathrm{OR}=0.2 ; 95 \%$ CI 0.1-0.6). In one other study, in PWID, no effect of DOT administered by an outreach nurse on completion rates of LTBI treatment was found $(\mathrm{OR}=1.1 ; 95 \%$ CI 0.5-2.1; moderate quality of evidence). However, when looking at the proportion of people who took all doses, the DOT group performed significantly better $(\mathrm{OR}=31.5$; 95 \% CI 14.1-70.6) [17].

Two more studies compared DOT to SAT, but were confounded: among case contacts with LTBI a shorter treatment regimen was given in the DOT than in the SAT group [20], and among PWID with LTBI the DOT group received methadone treatment whereas the SAT group did not [16]. Higher completion rates were found in the DOT group among both case contacts $(\mathrm{OR}=2.1$; $95 \%$ CI 1.92.3; low quality of evidence) and PWID (OR $=14.5$; $95 \%$ CI 5.1-42; very low quality of evidence).

Does treatment supported by (monetary) incentives result in higher initiation, adherence, or completion rates than treatment not supported by incentives in individuals eligible for LTBI treatment (Table 4)?

Two studies in PWID with LTBI found higher completion rates for LTBI treatment among those who received either a monetary incentive (adjusted OR $[\mathrm{aOR}]=32.0$; 
Table 1 Overview of determinants of LTBI treatment initiation, adherence and completion in the general population diagnosed with LTBI

\begin{tabular}{|c|c|c|c|c|c|}
\hline \multirow[t]{3}{*}{ Determinant } & \multirow[t]{3}{*}{ Specification determinant (vs. reference group) } & \multicolumn{4}{|c|}{ Number of articles } \\
\hline & & \multicolumn{2}{|c|}{ Positive association } & \multicolumn{2}{|c|}{ Inverse association } \\
\hline & & $P$ & $\mathrm{R}$ & $\mathrm{P}$ & $\mathrm{R}$ \\
\hline \multicolumn{6}{|c|}{ Determinants of LTBI treatment initiation } \\
\hline Age & Older age (vs. younger age) & - & $1[49]$ & - & $2[22,26]$ \\
\hline Gender & Men (vs. women) & - & $1[26]$ & - & $1[49]$ \\
\hline \multirow{4}{*}{$\begin{array}{l}\text { Sub-population } \\
\text { within general } \\
\text { population with } \\
\text { LTBI }\end{array}$} & $\begin{array}{l}\text { Refugee/immigrants (vs. born in country } \\
\text { of study) }\end{array}$ & $1[25]$ & $1[26]$ & - & - \\
\hline & $\begin{array}{l}\text { Immigrants born in WHO category } 3 \text { or } \\
5 \text { country (vs. category } 1 \text { country) }\end{array}$ & $1[25]$ & - & - & - \\
\hline & HCW (vs. no HCW) & - & - & - & $2[22,23]$ \\
\hline & Case contact (vs. no case contact) & $1[24]$ & $2[22,23]$ & - & - \\
\hline Education & Lower education level (vs. n.r.) & $1[24]$ & - & - & - \\
\hline Behaviour & $\begin{array}{l}\text { Alcohol use reported at baseline (vs. no } \\
\text { alcohol use reported) }\end{array}$ & - & - & - & $1[49]$ \\
\hline \multirow[t]{7}{*}{ Other } & $\begin{array}{l}\text { Continuity of primary care by consulting a } \\
\text { regular physician (vs. n.r.) }\end{array}$ & $1[24]$ & - & - & - \\
\hline & Pregnant (vs. not pregnant) & - & - & - & $1[47]$ \\
\hline & Prior incarceration (vs. n.r.) & $1[24]$ & - & - & - \\
\hline & $\begin{array}{l}\text { Fear of getting sick with TB without medicine } \\
\text { (vs. no fear of getting sick) }\end{array}$ & $1[24]$ & - & - & - \\
\hline & Previous BCG vaccination (vs. n.r.) & - & - & - & $1[22]$ \\
\hline & $\begin{array}{l}\text { Abnormal CXR findings consistent with } \\
\text { previous TB (vs. n.r.) }\end{array}$ & - & $1[22]$ & - & - \\
\hline & A non-employment reason for screening (vs. n.r.) & $1[24]$ & - & - & - \\
\hline \multicolumn{6}{|c|}{ Determinants of LTBI treatment adherence } \\
\hline Age & Older age (vs. younger age) & - & - & $1[75]$ & - \\
\hline Ethnicity & Bicultural $^{\mathrm{D}}$ (vs. Hispanic or non-Hispanic) & $1[75]$ & - & & - \\
\hline Education & Higher grades in school (vs. lower grades) & $1[75]$ & - & - & - \\
\hline Behaviour & Risk behaviours (vs. n.r.) ${ }^{\mathrm{E}}$ & - & - & $2[75,76]$ & - \\
\hline Adverse events & Some somatic complaints (vs. n.r.) & - & - & $1[76]$ & - \\
\hline \multicolumn{6}{|c|}{ Determinants of LTBI treatment completion } \\
\hline Age & Older (vs. younger) & $3[43,58]^{B, C}$ & $4[29,31,42,44]^{G}$ & $3[25,77,78]$ & $\begin{array}{l}6[23,28,30,41, \\
46,79]\end{array}$ \\
\hline Gender & Male (vs. female) & - & - & - & $2[30,44]$ \\
\hline \multirow[t]{7}{*}{ Ethnicity } & Hispanic/Latino ethnicity (vs. Asian ethnicity) & - & - & $1[78]$ & \\
\hline & White Hispanic (vs. black, non-Hispanic) & - & $1[30,34,46]$ & - & - \\
\hline & $\begin{array}{l}\text { Country of birth (i.e. Haiti, Dominican Republic, } \\
\text { China with HK or Vietnam) (vs. other countries) }\end{array}$ & $\begin{array}{l}\text { Varying results } \\
\text { found between } \\
\text { countries [80] }\end{array}$ & & & \\
\hline & Asian/Pacific Islander (vs. white) & - & $2[42,44]$ & - & - \\
\hline & $\begin{array}{l}\text { Region of origin (i.e. Latin America and Caribbean } \\
\text { or Asia and other) (vs. USA, Canada, Europe) }\end{array}$ & - & 1 [41] & - & - \\
\hline & Black race (vs. n.r.) & - & - & - & $1[29]^{G}$ \\
\hline & $\begin{array}{l}\text { Ethnicity (i.e. Asian, Non-Hispanic black or } \\
\text { Hispanic (vs. non-Hispanic white) }\end{array}$ & & 1 [31] & & \\
\hline
\end{tabular}


Table 1 Overview of determinants of LTBI treatment initiation, adherence and completion in the general population diagnosed with LTBI (Continued)

\begin{tabular}{|c|c|c|c|c|c|}
\hline \multirow{6}{*}{$\begin{array}{l}\text { Sub-population } \\
\text { within source } \\
\text { population }\end{array}$} & HCW (vs. no HCW) & - & - & - & $1[23]$ \\
\hline & Case contact (vs. no case contact) & - & $1[31]$ & - & $1[29]^{\mathrm{F}}$ \\
\hline & Currently homeless (vs. not currently homeless) & - & - & - & $2[30,32]$ \\
\hline & PWID (vs. no PWID) & - & - & - & $2[23,34]$ \\
\hline & Refugees/immigrants (vs. born in country of study) & $1[27]$ & $4[28-31]^{G}$ & & 2 [32] [33] \\
\hline & $\begin{array}{l}\text { Indication for LTBI treatment immunosuppression } \\
\text { (vs. case contact) }\end{array}$ & $1[43]^{c}$ & - & - & - \\
\hline \multirow[t]{3}{*}{ Health } & $\begin{array}{l}\text { History of hepatitis A, B or C (vs. no history of } \\
\text { liver disease) }\end{array}$ & $1[77]$ & - & - & - \\
\hline & $\begin{array}{l}\text { Other medications reported at baseline } \\
\text { (vs. none reported) }\end{array}$ & - & - & - & $1[29]^{F}$ \\
\hline & $\begin{array}{l}\text { Use of concomitant medications by women } \\
\text { (vs. no use of concomitant medication) }\end{array}$ & - & - & - & $1[49]$ \\
\hline \multirow[t]{2}{*}{ Behaviour } & (Excess) alcohol use (vs. no alcohol use) & - & - & - & $4[29,30,32,49]^{\mathrm{F}}$ \\
\hline & Smoking (vs. non-smoking) & $1[43]^{C}$ & - & - & - \\
\hline \multirow[t]{5}{*}{ Treatment } & Treatment without $\mathrm{H}$ (vs. treatment with $\mathrm{H}$ ) & $1[43]^{C}$ & $5[31,39-42]$ & - & - \\
\hline & 9-months H (vs. other regimens) & - & - & - & $1[23]$ \\
\hline & $\begin{array}{l}\text { Regimen choice offered (vs. no regimen } \\
\text { choice offered) }\end{array}$ & - & $1[79]$ & - & - \\
\hline & Twice weekly RZ (vs. daily RZ) & - & $1[81]$ & - & - \\
\hline & DOT (vs. SAT) & - & $3[31,44,45]$ & - & - \\
\hline \multirow[t]{2}{*}{ Adverse events } & Adverse events (vs. no adverse events) & - & - & - & $\begin{array}{l}7[30,33,41 \\
46-49]\end{array}$ \\
\hline & $\begin{array}{l}\text { Adverse events (i.e. grade } 1 \text { or } 2 \text { hepatotoxicity, } \\
\text { grade } 3 \text { or } 4 \text { hepatotoxicity or adverse events } \\
\text { other than hepatotoxicity) (vs. n.r.) }\end{array}$ & $\begin{array}{l}\text { Conflicting results } \\
\text { found between } \\
\text { adverse events [51] }\end{array}$ & & & \\
\hline \multirow[t]{13}{*}{ Other } & $\begin{array}{l}\text { Not having been incarcerated within } 6 \text { months } \\
\text { of diagnosis (vs. n.r.) }\end{array}$ & $1[25]$ & - & - & - \\
\hline & $\begin{array}{l}\text { Referral reason (i.e. correctional/rehabilitation or } \\
\text { postpartum women) (vs. TST positive from screening) }\end{array}$ & - & - & - & $1[28]$ \\
\hline & $\begin{array}{l}\text { Risk group (i.e. contact, medical risk }{ }^{\mathrm{H}} \text {, population } \\
\text { risk') (vs. low risk') }\end{array}$ & - & $1[31]$ & - & - \\
\hline & $\begin{array}{l}\text { Cause of screening/referral (i.e. asylum seekers } \\
\text { or contacts) (vs. anti-TNF-a candidates) }\end{array}$ & - & - & - & $1[82]$ \\
\hline & Fear for venepuncture (vs. n.r.) & - & - & $1[83]$ & - \\
\hline & Low TB risk perception (vs. n.r.) & - & - & $1[83]$ & - \\
\hline & $\begin{array}{l}\text { Plan to tell friends or family about LTBI } \\
\text { diagnosis (vs. n.r.) }\end{array}$ & $1[24]$ & - & - & - \\
\hline & $\begin{array}{l}\text { Home situation (i.e. child living with no or one } \\
\text { natural parent) (vs. living with both natural parents) }\end{array}$ & - & - & $1[27]$ & - \\
\hline & Spanish language (vs. non-Spanish language) & - & $1[60]$ & - & - \\
\hline & $\begin{array}{l}\text { Resident in a congregate setting (vs. never } \\
\text { or unknown) }\end{array}$ & - & - & - & $1[23]$ \\
\hline & $\begin{array}{l}\text { Missed appointment call or letter (vs. no missed } \\
\text { appointment call) }\end{array}$ & - & - & - & $1[60]$ \\
\hline & No medical insurance (vs. medical insurance) & - & - & - & $1[47]$ \\
\hline & $\begin{array}{l}\text { Clinic attendance before treatment (vs. clinic } \\
\text { non-attendance before treatment) }\end{array}$ & - & $1[79]$ & - & - \\
\hline
\end{tabular}


Table 1 Overview of determinants of LTBI treatment initiation, adherence and completion in the general population diagnosed with LTBI (Continued)

\begin{tabular}{|c|c|c|c|}
\hline $\begin{array}{l}\text { Presumed non-recent TB infection (vs. presumed } \\
\text { recent TB infection) }\end{array}$ & - & - & - \\
\hline $\begin{array}{l}\text { Public health nurse referral (vs. no public health } \\
\text { nurse referral) }\end{array}$ & - & - & - \\
\hline
\end{tabular}

BCG Bacillus Calmette-Guérin; CXR chest radiograph; DOT directly observed therapy; $H$ isoniazid; $H C W$ healthcare worker; $H K$ Hong Kong; i.e. id est; $L T B I$ latent tuberculosis infection; n.r. not reported; PWID people who inject drug; $R Z$ rifampicin and pyrazinamide; SAT self-administered therapy; TB tuberculosis; TNF tumor necrosis factor; TST tuberculin skin test; USA United States of America; WHO World Health Organisation

${ }^{A}$ WHO defined 5 categories of TB prevalence based on 1 st (least prevalent) to 5 th (most prevalent). ${ }^{B}$ Data analysed in individuals that underwent three

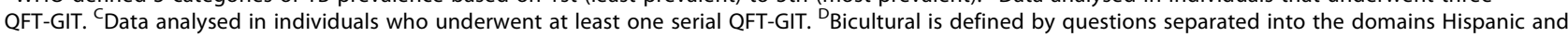
non-Hispanic, considering language use, linguistic proficiency and electronic media use. Individuals scoring high in both domains are considered bicultural. ERisk behaviours: ever used alcohol, cigarettes, marijuana, been expelled or suspended from school, or been in a physical fight. ${ }^{\mathrm{F}}$ Data analysed in Hispanic subjects for one study. ${ }^{\mathrm{G}}$ Data analysed in non-Hispanic subjects for one study ${ }^{\mathrm{H}}$ Persons with medical risk factors such as having a TST conversion within two years of a negative TST, HIV infection, untreated or partially treated prior TB, suspected TB with an abnormal chest radiograph, being younger than five years of age with a positive TST, or having a clinical condition associated with an increased risk of TB disease. 'persons with population risk factors such as: recent immigrants to the USA ( 5 years) from countries with high TB prevalence, homeless persons, residents and employees of congregate settings such as prisons and jails, and healthcare facilities. Jpersons with low risk for developing TB disease (no case contact, no medical risk, no population risk factors)

$95 \%$ CI 7.1-145; moderate quality of evidence) [55] or methadone treatment $(\mathrm{OR}=14.5$; $95 \%$ CI 5.0-42; very low quality of evidence) [16] compared to those who received no incentive. The results from the methadone treatment study were confounded, however, by the use of DOT in the methadone treatment group and SAT in the control group. The provision of food or transportation vouchers to released inmates with LTBI if they attended a TB clinic upon release $(\mathrm{OR}=1.1$; $95 \%$ CI 0.5-2.4; moderate quality of evidence) [15] did not lead to better completion rates. In another study, no difference was found between the provision of cash-incentives versus non-cashincentives to homeless individuals with LTBI $(\mathrm{OR}=1.7$; $95 \%$ CI 0.7-4.3; low quality of evidence) [56].

\section{Do social interventions result in higher initiation,} adherence, or completion rates than standard care in individuals eligible for LTBI treatment (Table 5)?

Adherence coaching among the general population with LTBI at clinics (low quality of evidence) and a cultural intervention among immigrants (very low quality of evidence) resulted in better adherence [19, 57]. Social interventions were found to improve completion rates of LTBI treatment compared to the standard care group in all but one study, which provided peer-support among PWID with LTBI $(\mathrm{OR}=1.0$; $95 \%$ CI 0.7-1.5; high quality of evidence) and found no effect on completion [17]. Counselling and contingency contracting, adherence coaching and self-esteem counselling, and peer-based interventions in the general population showed better completion rates (sOR $=1.4$; $95 \%$ CI 1.1-19; low heterogeneity, high quality of evidence) $[19,27,58]$ (Fig. 3).

Education among inmates $(\mathrm{OR}=2.2$; $95 \%$ CI 1.0-4.7; moderate quality of evidence) [15], nurse case management among homeless individuals $(\mathrm{aOR}=3.0$; 95 \% CI 2.2-4.2; high quality of evidence) [35], and case management with attention for the cultural background of each individual among immigrants $(\mathrm{aOR}=7.8 ; 95 \%$ CI 5.7-10.7; low quality of evidence) [18] improved completion. The latter study also found that this intervention led to higher initiation rates $(\mathrm{OR}=2.7 ; 95 \% \mathrm{CI}$ 1.9-3.8; low quality of evidence).

\section{Do interventions other than short treatment, directly observed therapy, incentives or social interventions result in higher initiation, adherence, or completion rates than standard care in individuals eligible for LTBI treatment (Table 6)?}

One study showed that the use of IGRAs rather than TSTs for diagnosis of LTBI improved the initiation rate of LTBI treatment in healthcare workers with LTBI $(\mathrm{OR}=8.8$; $95 \%$ CI 3.1-23; very low quality of evidence) [59].

Three retrospective studies performed in the general population with LTBI showed significantly higher completion rates in the groups that received DOT, behaviour modification techniques in combination with incentives, or home to clinic follow-up, respectively [28, 44, 60] (see Additional file 4).

\section{Discussion}

To the best of our knowledge, this is the first review to systematically and comprehensively summarise data on any determinant of, and intervention to improve, LTBI treatment initiation, adherence and completion in all types of populations.

\section{Determinants}

The most frequently found determinants of treatment completion in our review were patient-related (i.e. type of population with LTBI, demographic factors, drug/alcohol abuse), therapy-related (e.g. short therapy regimens, DOT, occurrence of adverse events), and socioeconomic (e.g. unemployment, lack of social support). Unfavourable socio-economic factors were consistently associated with poor completion of LTBI therapy. These results should be interpreted with care, since 
Table 2 Grading of the body of evidence for effectiveness of short versus long LTBI treatment. Question: Does short LTBI treatment result in higher initiation, adherence, or completion rates than long LTBI treatment in individuals eligible for LTBI treatment?

\begin{tabular}{|c|c|c|c|c|c|c|c|c|c|c|c|c|}
\hline \multirow{3}{*}{$\begin{array}{l}\text { No of studies } \\
\text { (No of participants) }\end{array}$} & \multirow{3}{*}{ Design } & \multirow{3}{*}{$\begin{array}{l}\text { Population } \\
\text { Intervention }\end{array}$} & \multicolumn{5}{|c|}{ Quality assessment } & \multirow{3}{*}{$\begin{array}{l}\mathrm{n} / \mathrm{N}=\%^{\mathrm{a}} \\
\text { Short LTBI } \\
\text { treatment } \\
\text { Long LTBI } \\
\text { treatment }\end{array}$} & \multicolumn{2}{|l|}{ Effect } & \multirow[t]{3}{*}{ Quality } & \multirow[t]{3}{*}{ Importance } \\
\hline & & & \multirow[t]{2}{*}{ Risk of bias } & \multirow[t]{2}{*}{ Inconsistency } & \multirow[t]{2}{*}{ Indirectness } & \multirow[t]{2}{*}{ Imprecision } & \multirow[t]{2}{*}{ Other considerations } & & \multirow[t]{3}{*}{ OR $(95 \% C l)^{b}$} & \multirow{3}{*}{$\begin{array}{l}\text { Absolute } \\
\text { (per } 1000 \\
(95 \% \mathrm{Cl}))^{c}\end{array}$} & & \\
\hline & & & & & & & & & & & & \\
\hline \multicolumn{11}{|l|}{ Initiation } & & \\
\hline $0(0)$ & $\begin{array}{l}\text { No evidence } \\
\text { available }\end{array}$ & - & - & - & - & - & - & - & - & - & - & Critical \\
\hline \multicolumn{13}{|l|}{ Adherence } \\
\hline \multirow[t]{2}{*}{$2(822)[21,50]$} & \multirow[t]{2}{*}{ RCT } & Case contacts & \multirow[t]{2}{*}{ Serious $^{d}$} & \multirow[t]{2}{*}{ Not serious } & \multirow[t]{2}{*}{ Not serious } & \multirow[t]{2}{*}{ Not serious } & \multirow[t]{2}{*}{ None } & $\begin{array}{l}344 / 391=88 \% \\
\text { (range: } 82-92 \% \text { ) }\end{array}$ & \multirow[t]{2}{*}{$1.5(1.0-2.3)$} & \multirow[t]{2}{*}{$55(4-92)$} & \multirow[t]{2}{*}{$\begin{array}{l}\oplus \oplus \oplus \mathrm{O} \\
\text { Moderate }\end{array}$} & \multirow[t]{2}{*}{ Critical } \\
\hline & & $\begin{array}{l}3 \mathrm{HR} \text { or } 2 \mathrm{RZ} \text { vs. } \\
6 \mathrm{H} \text { or } 9 \mathrm{H}\end{array}$ & & & & & & $\begin{array}{l}353 / 431=82 \% \\
\text { (range:7-86 \%) }\end{array}$ & & & & \\
\hline \multicolumn{13}{|l|}{ Completion } \\
\hline \multirow[t]{2}{*}{1 (352) [21] } & \multirow[t]{2}{*}{ RCT } & Case contacts & \multirow[t]{2}{*}{ Serious $^{\mathrm{e}}$} & \multirow[t]{2}{*}{ Not serious } & \multirow[t]{2}{*}{ Not serious } & Not serious & None & $106 / 153=69 \%$ & $0.8(0.5-1.3)$ & $-46(-156-49)$ & $\oplus \oplus \oplus \bigcirc$ & Critical \\
\hline & & $2 \mathrm{RZ}$ vs. $6 \mathrm{H}$ & & & & & & $145 / 199=73 \%$ & & & & \\
\hline 1 (7731) [20] & RCT & Case contacts & Very serious $^{f}$ & Not serious & Not serious & Not serious & None & $3273 / 3986=82 \%$ & $2.1(1.9-2.3)$ & 134 (119-146) & $\oplus \oplus \mathrm{OO}$ & Critical \\
\hline & & $\begin{array}{l}3 \mathrm{H}+\mathrm{RPT}+\mathrm{DOT} \\
\text { vs. } 9 \mathrm{H}+\mathrm{SAT}\end{array}$ & & & & & & $2585 / 3745=69 \%$ & & & & \\
\hline 1 (590) [38] & RCT & Immigrants & Serious $^{g}$ & Not serious & Not serious & Not serious & None & $213 / 296=72 \%$ & $2.5(1.7-3.6)$ & $206(125-273)$ & $\oplus \oplus \oplus 0$ & Critical \\
\hline & & $3 \mathrm{HR}$ vs. $6 \mathrm{H}$ & & & & & & $154 / 294=52 \%$ & & & Moderate & \\
\hline 3 (1552) [51-53] & RCT & $\begin{array}{l}\text { General } \\
\text { population }\end{array}$ & Serious $^{\mathrm{h}}$ & Not serious & Not serious & Not serious & None & $\begin{array}{l}\text { 568/785 = } 72 \% \\
\text { (range: 61-91\%) }\end{array}$ & $1.9(1.1-3.5)$ & $141(23-241)$ & $\begin{array}{l}\oplus \oplus \oplus \mathrm{O} \\
\text { Moderate }\end{array}$ & Critical \\
\hline & & $\begin{array}{l}2 R Z \text { or } 4 R \text { vs. } \\
6 \mathrm{H} \text { or } 9 \mathrm{H}\end{array}$ & & & & & & $\begin{array}{l}459 / 767=60 \% \\
\text { (range: } 57-76 \% \text { ) }\end{array}$ & & & & \\
\hline
\end{tabular}

Bibliography: Spyridis et al. 2007 [50]; Tortajada et al. 2005 [21]; Sterling et al. 2011 [20]; Jimenez-Fuentes et al. 2013 [38]; Menzies et al. 2008 [53]; Menzies et al. 2004 [52]; Jasmer et al. 2002 [51]

$n / N$ No of individuals with LTBI who initiated, or adhered to or completed treatment/total number of subjects; Cl confidence interval; DOT directly observed therapy; $3 H, 6 H, 9 H 3,6$ or 9 months isoniazid; $3 H R$

3 months isoniazid + rifampicin; $O R$ odds ratio; $4 R$ four months rifampin; $R C T$ randomised controlled trial; RPT rifapentine; $2 R Z 2$ months rifampicin + pyrazinamide; SAT self-administered therapy

alf $>1$ articles, weighed pooled point estimates and $95 \% \mathrm{Cl}$ were calculated

$\mathrm{b}_{\text {If }}>1$ articles, weighed pooled estimates and $95 \% \mathrm{Cl}$ were calculated using a random effects model (without quality index)

"Calculated via GradePro

Pro

'Spyridis et al. 2007 [50]: no blinding. Tortajada et al. 2005 [21]: no blinding; use of unvalidated patient-reported outcomes (pill count and calendar annotations); early termination (due to higher toxicity in 2RZ arm, unplanned interim analysis); dissimilarities between treatment arms (more foreign-born in 2RZ); unequal number of patients in the two groups

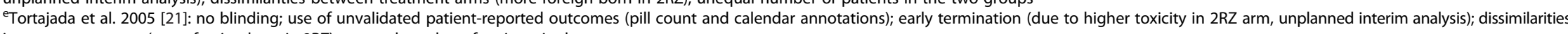
in treatment groups (more foreign-born in 2RZ); unequal number of patients in the two groups

'Sterling et al. 2011 [20]: unclear allocation concealment; no blinding; use of unvalidated patient-reported outcomes (pill count and self-report); dissimilarities between treatment arms (with respect to North American Indians, subjects enrolled in a cluster, homelessness); exposure bias (DOT only in short treatment arm)

9Jimenez-Fuentes et al. 2013 [38]: unclear allocation concealment; no blinding; dissimilarities between treatment arms (with respect to sex and undocumented migration status)

${ }^{\mathrm{h}}$ Menzies et al. 2004 [52]: unclear allocation concealment; no blinding. Menzies et al. 2008 [53]: unclear allocation concealment; no blinding; early termination (due to lower toxicity in 4R arm, planned interim analysis). Jasmer et al. 2002 [51]: lack of allocation concealment (alternate weeks); inadequate sequence generation (alternate weeks); no blinding; unclear treatment adherence assessment; dissimilarities between treatment

arms (born outside United States, age $>35$ years) 
Table 3 Grading of the body of evidence for effectiveness of DOT versus SAT. Question: Does DOT result in higher initiation, adherence, or completion rates than SAT in individuals eligible for LTBI treatment?

\begin{tabular}{|c|c|c|c|c|c|c|c|c|c|c|c|c|}
\hline \multirow{3}{*}{$\begin{array}{l}\text { No of studies } \\
\text { (No of participants) }\end{array}$} & \multirow{3}{*}{ Design } & \multirow{3}{*}{$\begin{array}{l}\text { Population } \\
\text { treatment } \\
\text { intervention }\end{array}$} & \multicolumn{5}{|c|}{ Quality assessment } & \multirow{4}{*}{$\begin{array}{l}\mathrm{n} / \mathrm{N}=\% \\
\text { DOT } \\
\text { SAT }\end{array}$} & \multicolumn{2}{|l|}{ Effect } & \multirow[t]{4}{*}{ Quality } & \multirow[t]{3}{*}{ Importance } \\
\hline & & & Risk of bias & Inconsistency & Indirectness & Imprecision & Other & & \multirow[t]{3}{*}{ OR $(95 \% \mathrm{Cl})$} & \multirow{3}{*}{$\begin{array}{l}\text { Absolute }^{\mathrm{a}} \text { (per } \\
1000(95 \% \mathrm{Cl}))\end{array}$} & & \\
\hline & & & & & & & & & & & & \\
\hline \multicolumn{9}{|l|}{ Initiation } & & & & \\
\hline $0(0)$ & $\begin{array}{l}\text { No evidence } \\
\text { available }\end{array}$ & - & - & - & - & - & - & - & - & - & - & Critical \\
\hline \multicolumn{13}{|l|}{ Adherence } \\
\hline $0(0)$ & $\begin{array}{l}\text { No evidence } \\
\text { available }\end{array}$ & - & - & - & - & - & - & - & - & - & - & Critical \\
\hline \multicolumn{13}{|l|}{ Completion } \\
\hline \multirow[t]{2}{*}{1 (199) [17] } & \multirow[t]{2}{*}{ RCT } & PWID ${ }^{\mathrm{b}}$ long $\mathrm{H}$ & \multirow[t]{2}{*}{ Serious $^{c}$} & \multirow[t]{2}{*}{ Not serious } & \multirow[t]{2}{*}{ Not serious } & \multirow[t]{2}{*}{ Not serious } & \multirow[t]{2}{*}{ None } & $79 / 99=80 \%$ & \multirow[t]{2}{*}{$1.1(0.5-2.1)$} & \multirow[t]{2}{*}{$15(-137-98)$} & \multirow{2}{*}{$\begin{array}{l}\oplus \oplus \oplus \mathrm{O} \\
\text { Moderate }\end{array}$} & \multirow{2}{*}{ Critical } \\
\hline & & $\begin{array}{l}\text { Outreach DOT vs. } \\
\text { SAT }\end{array}$ & & & & & & $79 / 100=79 \%$ & & & & \\
\hline \multirow[t]{2}{*}{1 (111) [16] } & \multirow[t]{2}{*}{ RCT } & PWID ${ }^{\mathrm{b}}$ long $\mathrm{H}$ & \multirow[t]{2}{*}{ Very serious $^{d}$} & \multirow[t]{2}{*}{ Not serious } & \multirow[t]{2}{*}{ Not serious } & \multirow[t]{2}{*}{ Serious $^{\mathrm{e}}$} & \multirow[t]{2}{*}{ None } & $49 / 72=68 \%$ & \multirow[t]{2}{*}{$14.5(5.0-42)$} & \multirow[t]{2}{*}{$552(296-732)$} & \multirow{2}{*}{$\begin{array}{l}\oplus \mathrm{OOO} \\
\text { Very low }\end{array}$} & \multirow[t]{2}{*}{ Critical } \\
\hline & & $\begin{array}{l}\text { DOT + Methadone } \\
\text { treatment vs. SAT } \\
\text { + no incentive }\end{array}$ & & & & & & $5 / 39=13 \%$ & & & & \\
\hline 1 (7731) [20] & RCT & Case contacts & Very serious ${ }^{9}$ & Not serious & Not serious & Not serious & None & $3273 / 3986=82 \%$ & $2.1(1.9-2.3)$ & $134(119-146)$ & $\oplus \oplus \bigcirc \bigcirc$ & Critical \\
\hline & & $\begin{array}{l}\mathrm{DOT}+3 \mathrm{H}+\mathrm{RPT} \\
\text { vs. SAT + long H }\end{array}$ & & & & & & $2585 / 3745=69 \%$ & & & & \\
\hline 1 (135) [54] & RCT & Immigrants long $\mathrm{H}$ & Serious $^{h}$ & Not serious & Not serious & Serious $^{\mathrm{e}}$ & None & $6 / 82=7.3 \%$ & $0.1(0.04-0.3)$ & $-342(-239--387)$ & $\oplus \oplus \bigcirc$ & Critical \\
\hline & & $\begin{array}{l}\text { Clinic-based DOT' } \\
\text { vs. SAT dailyc }\end{array}$ & & & & & & $22 / 53=41 \%$ & & & Low & \\
\hline
\end{tabular}

Bibliography: Chaisson et al. 2001 [17]; Batki et al. 2002 [16]; Sterling et al. 2011 [20]; Matteelli et al. 2000 [54]

$n / N$ No of individuals with LTBI who initiated, or adhered to or completed treatment/total number of subjects; $C l$ confidence interval; DOT directly observed therapy; $H, 3 H$ ( 3 months) isoniazid; OR odds ratio; PWID people who inject drugs; $R C T$ randomized controlled trial; RPT rifapentine; SAT self-administered therapy

${ }^{a}$ Calculated via GradePro

bBoth studies with PWID population are presented separately, since one of the studies applies DOT + an incentive as intervention

'Chaisson et al. 2001 [17]: unclear allocation concealment; no blinding; use of unvalidated patient-reported outcomes in SAT arm (self-report; urine tests and MEMS in a subset of patients in this study show that self-reported adherence was greatly overestimated, thereby possibly underestimating the effect of DOT)

${ }^{\mathrm{d}}$ Batki et al. 2002 [16]: no blinding; use of unvalidated patient-reported outcomes in SAT arm (monthly medication pick-up); dissimilarities between treatment arms (age, Addiction Severity Index psychiatric and Beck depression inventory); exposure bias (incentive in DOT arm)

depression inventory); exposu
total number of events $<125$

fotal number of events $<125$

9Sterling et al. 2011 [20]: unclear allocation concealment; no blinding; use of unvalidated patient-reported outcomes in SAT arm (pill count and self-report); dissimilarities between treatment arms (with respect to North American Indians, subjects enrolled in a cluster, homelessness); exposure bias (short treatment in DOT arm)

${ }^{h}$ Matteelli et al. 2000 [54]: unclear allocation concealment; no blinding; very large loss to follow-up; unclear treatment adherence assessment in SAT arm; unequal numbers in treatment arms; early termination (due to low completion rates in DOT arm). Early termination partially accounts for the low numbers in this study, and as we already downgraded for this (serious imprecision), we decided not to downgrade for it again in the risk of bias

'Most likely DOT, however terminology not very clear in the methods and results sections of the article 
Table 4 Grading of the body of evidence for the effectiveness of (monetary) incentives. Question: Does treatment supported by (monetary) incentives result in higher initiation, adherence, or completion rates than treatment not supported by incentives in individuals eligible for LTBI treatment?

\begin{tabular}{|c|c|c|c|c|c|c|c|c|c|c|c|c|}
\hline \multirow{3}{*}{$\begin{array}{l}\text { No of studies } \\
\text { (No of participants) }\end{array}$} & \multirow{3}{*}{ Design } & \multirow{3}{*}{$\begin{array}{l}\text { Population - treatment- } \\
\text { intervention }\end{array}$} & \multicolumn{5}{|c|}{ Quality assessment } & \multirow{3}{*}{$\begin{array}{l}\mathrm{n} / \mathrm{N}=\% \\
\text { Incentives } \\
\text { No incentives }\end{array}$} & \multicolumn{2}{|l|}{ Effect } & \multirow[t]{3}{*}{ Quality } & \multirow[t]{3}{*}{ Importance } \\
\hline & & & Risk of bias & Inconsistency & Indirectness & Imprecision & Other & & OR $(95 \% \mathrm{Cl})$ & Absolute $^{a}$ & & \\
\hline & & & & & & & considerations & & & $\begin{array}{l}(\text { per } 1000 \\
(95 \% C I))\end{array}$ & & \\
\hline \multicolumn{13}{|l|}{ Initiation } \\
\hline $0(0)$ & $\begin{array}{l}\text { No evidence } \\
\text { available }\end{array}$ & - & - & - & - & - & - & - & - & - & - & Critical \\
\hline \multicolumn{13}{|l|}{ Adherence } \\
\hline $0(0)$ & $\begin{array}{l}\text { No evidence } \\
\text { available }\end{array}$ & - & - & - & - & - & - & - & - & - & - & Critical \\
\hline \multicolumn{13}{|l|}{ Completion } \\
\hline \multirow[t]{2}{*}{$1(111)[16]$} & \multirow[t]{2}{*}{ RCT } & PWID - long $\mathrm{H}^{\mathrm{b}}$ & \multirow[t]{2}{*}{ Very serious $^{c}$} & \multirow[t]{2}{*}{ Not serious } & \multirow[t]{2}{*}{ Not serious } & \multirow[t]{2}{*}{ Serious $^{d}$} & \multirow[t]{2}{*}{ None } & $49 / 72=68 \%$ & \multirow[t]{2}{*}{$14.5(5.0-42)$} & \multirow[t]{2}{*}{$552(296-732)$} & \multirow{2}{*}{$\begin{array}{l}\oplus \mathrm{OOO} \\
\text { Very low }\end{array}$} & \multirow[t]{2}{*}{ Critical } \\
\hline & & $\begin{array}{l}\text { Methadone treatment } \\
+ \text { DOT vs. no incentive } \\
+ \text { SAT }\end{array}$ & & & & & & $5 / 39=13 \%$ & & & & \\
\hline \multirow[t]{2}{*}{$1(108)$ [55] } & \multirow[t]{2}{*}{ RCT } & PWID - long $H^{b}$ & \multirow[t]{2}{*}{ Not serious $^{f}$} & \multirow[t]{2}{*}{ Not serious } & \multirow[t]{2}{*}{ Not serious } & \multirow[t]{2}{*}{ Serious $^{d}$} & \multirow[t]{2}{*}{ None } & $29 / 53=53 \%$ & \multirow[t]{2}{*}{$32.0(7.1-145)^{9}$} & \multirow[t]{2}{*}{$511(174-809)$} & \multirow{2}{*}{$\begin{array}{l}\oplus \oplus \oplus \mathrm{O} \\
\text { Moderate }\end{array}$} & \multirow[t]{2}{*}{ Critical } \\
\hline & & $\begin{array}{l}\text { Monetary incentive vs. } \\
\text { no incentive }\end{array}$ & & & & & & $2 / 55=3.6 \%$ & & & & \\
\hline \multirow[t]{2}{*}{1 (216) [15] } & \multirow[t]{2}{*}{ RCT } & Inmates $^{h}$ - long H & Not serious' & Not serious & Not serious & Serious $^{d}$ & None & $14 / 113=12 \%$ & $1.1(0.5-2.4)^{j}$ & $7(-58-124)$ & $\oplus \oplus \oplus \mathrm{O}$ & Critical \\
\hline & & $\begin{array}{l}\text { Non-cash }{ }^{\mathrm{k}} \text { incentive vs. } \\
\text { no incentive }\end{array}$ & & & & & & $12 / 103=12 \%$ & & & Moderate & \\
\hline 1 (119) [56] & RCT & $\begin{array}{l}\text { Homeless - long H or } \\
\text { short HR }\end{array}$ & Serious' & Not serious & Not serious & Serious $^{d}$ & None & $58 / 68=85 \%$ & $1.7(0.7-4.3)$ & $80(-69-164)$ & $\begin{array}{l}\oplus \oplus \bigcirc \bigcirc \\
\text { Low }\end{array}$ & Critical \\
\hline & & $\begin{array}{l}\text { Cash vs. non-cash } \\
\text { incentive }^{m}\end{array}$ & & & & & & $44 / 57=77 \%$ & & & & \\
\hline
\end{tabular}

Bibliography: Tulsky et al. 2004 [56]; Batki et al. 2002 [16]; Malotte et al. 2001 [55]; White et al. 2002 [15]

$\mathrm{n} / \mathrm{N}$ : No of individuals with LTBI who initiated, or adhered to or completed treatment/total number of subjects; Cl: confidence interval; DOT: directly observed therapy; H: isoniazid; HR: isoniazid and rifampicin;

OR: odds ratio; PWID: people who inject drugs; RCT: randomised controlled trial

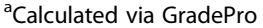

${ }^{\mathrm{b}}$ Both studies with PWID population are presented separately, since one of the studies applies incentive + DOT as intervention

${ }^{c}$ Malotte et al. 2001 [55]: unclear sequence generation; partly blinded

${ }^{\mathrm{d}}$ Batki et al. 2002 [16]: no blinding; use of unvalidated patient-reported outcomes in SAT arm (monthly medication pick-up); dissimilarities between treatment arms (age, Addiction Severity Index psychiatric and Beck depression inventory); exposure bias (DOT in incentive arm)

${ }^{\mathrm{e}}$ Approximately half of the intervention group (37/72) also received substance abuse counselling

Approximately half of the intervention

${ }^{9}$ Adjusted OR, adjusted for: treatment condition, recruitment status, binge drinking

hinmates who started treatment in jail and were released before treatment completion

'Tulsky et al. 2004 [56]: partly blinded; dissimilarities between treatment arms (primary housing in last year shelter/street; not found to be an independent predictor of completion in this study)this study presents data

for incentive vs. another incentive (rather than vs. no incentive)

'Adjusted OR, not reported which factors this OR was adjusted for

${ }^{k}$ \$25 equivalent in food or transportation vouchers

Total number of events $<125$

mPatients with normal chest X-rays prescribed $\mathrm{H}$, while those with evidence of old TB on chest X-ray were prescribed HR. Participants randomly assigned to the cash or non-cash incentive. Non-cash incentives

consisted of a choice of $\$ 5$ equivalent in fast-food or grocery store coupons, phone cards or bus tokens 
Table 5 Grading of body of evidence for the effectiveness of social interventions. Question: Do social interventions result in higher initiation, adherence, or completion rates than usual care in individuals eligible for LTBI treatment?

\begin{tabular}{|c|c|c|c|c|c|c|c|c|c|c|c|c|}
\hline \multirow{3}{*}{$\begin{array}{l}\text { No of } \\
\text { studies } \\
\text { (No of } \\
\text { participants) }\end{array}$} & \multirow{4}{*}{ Design } & \multirow{4}{*}{ Population intervention ${ }^{\mathrm{b}}$} & \multicolumn{5}{|c|}{ Quality assessment } & \multirow{4}{*}{$\begin{array}{l}\mathrm{n} / \mathrm{N}=\%^{\mathrm{a}} \\
\text { Social } \\
\text { intervention } \\
\text { No social } \\
\text { intervention }\end{array}$} & \multicolumn{2}{|l|}{ Effect } & \multirow[t]{4}{*}{ Quality } & \multirow[t]{4}{*}{ Importance } \\
\hline & & & Risk of bias & Inconsistency & Indirectness & Imprecision & $\begin{array}{l}\text { Other } \\
\text { considerations }\end{array}$ & & \multirow[t]{3}{*}{$\mathrm{OR}(95 \% \mathrm{Cl})^{\mathrm{c}}$} & \multirow{3}{*}{$\begin{array}{l}\text { Absolute }^{d} \\
\text { (per } 1000 \\
(95 \% \text { Cl)) }\end{array}$} & & \\
\hline & & & & & & & & & & & & \\
\hline Initiation & & & & & & & & & & & & \\
\hline \multirow[t]{2}{*}{1 (946) [18] } & \multirow{4}{*}{$\begin{array}{l}\text { Observational } \\
\text { study }\end{array}$} & Immigrants & \multirow[t]{4}{*}{ Not serious $^{e}$} & \multirow[t]{4}{*}{ Not serious } & \multirow[t]{4}{*}{ Not serious } & \multirow[t]{4}{*}{ Not serious } & \multirow[t]{4}{*}{ None } & $389 / 442=88 \%$ & \multirow[t]{2}{*}{$2.7(1.9-3.8)$} & \multirow[t]{4}{*}{$149(107-181)$} & \multirow{4}{*}{$\begin{array}{l}\oplus \oplus \mathrm{OO} \\
\text { Low }\end{array}$} & \multirow[t]{4}{*}{ Critical } \\
\hline & & Cultural case management & & & & & & $557 / 762=73 \%$ & & & & \\
\hline \multirow{2}{*}{\multicolumn{2}{|c|}{ Adherence }} & & & & & & & & & & & \\
\hline & & & & & & & & $\mathrm{N}$ & $\begin{array}{l}\text { Cumulative } \\
\text { mean number } \\
\text { of pills taken } \\
\text { over } 9 \text { months }\end{array}$ & & & \\
\hline \multirow[t]{2}{*}{1 (286) [19] } & \multirow[t]{2}{*}{ RCT } & General population & \multirow[t]{2}{*}{ Not serious ${ }^{9}$} & \multirow[t]{2}{*}{ Not serious } & \multirow[t]{2}{*}{ Not serious } & \multirow[t]{2}{*}{ Serioush } & \multirow[t]{2}{*}{ None } & 92 & 180 & \multirow[t]{2}{*}{-} & \multirow{2}{*}{$\begin{array}{l}\oplus \oplus \mathrm{OO} \\
\text { Low }\end{array}$} & Critical \\
\hline & & $\begin{array}{l}\text { Adherence } \\
\text { coaching }\end{array}$ & & & & & & 98 & 151 & & & \\
\hline 1 (184) [57] & Observational & Immigrants & Not seriousi & Not serious & Not serious & Serious & None & 53 & 157 & - & $\oplus \mathrm{OOO}$ & Critical \\
\hline & & $\begin{array}{l}\text { Cultural } \\
\text { intervention }\end{array}$ & & & & & & 131 & 129 & & very low & \\
\hline Completion & & & & & & & & & & & & \\
\hline $\begin{array}{l}3(928) \\
{[19,27,58]}\end{array}$ & RCT & $\begin{array}{l}\text { General } \\
\text { population }\end{array}$ & Not serious ${ }^{j}$ & Not serious & Not serious & Not serious & None & $\begin{array}{l}331 / 515=64 \% \\
\text { (range: } 46-84 \% \text { ) }\end{array}$ & $1.4(1.1-1.9)$ & $78(53-80)$ & $\begin{array}{l}\oplus \oplus \oplus O \\
\text { High }\end{array}$ & Critical \\
\hline & & $\begin{array}{l}\text { Counsellor/contingency } \\
\text { contracting \& adherence } \\
\text { coaching/self-esteem } \\
\text { counselling \& peer based }\end{array}$ & & & & & & $\begin{array}{l}253 / 413=61 \% \\
\text { (range: } 38-76 \% \text { ) }\end{array}$ & & & & \\
\hline 1 (946) [18] & Observational & Immigrants & Not serious $^{\mathrm{e}}$ & Not serious & Not serious & Not serious & None & $319 / 389=82 \%$ & $7.8(5.7-10.7)$ & $452(400-494)$ & $\oplus \oplus \bigcirc \bigcirc$ & Critical \\
\hline & study & $\begin{array}{l}\text { Case management taking } \\
\text { into account cultural } \\
\text { background }\end{array}$ & & & & & & $205 / 557=37 \%$ & & & Low & \\
\hline 1 (216) [15] & RCT & Inmates ${ }^{k}$ & Not serious' & Not serious & Not serious & Serious $^{m}$ & None & $24 / 106=23 \%$ & $2.2(1.0-4.7)^{n}$ & $108(4-267)$ & $\oplus \oplus 0$ & Critical \\
\hline & & Education & & & & & & $12 / 103=12 \%$ & & & & \\
\hline 1 (520) [35] & $\mathrm{RCT}$ & Homeless & Not serious $^{\circ}$ & Not serious & Not serious & Not serious & None & $173 / 279=62 \%$ & $3.0(2.2-4.2)^{\mathrm{p}}$ & 268 (189-339) & $\oplus \oplus \oplus \oplus$ & Critical \\
\hline & & Nurse case management & & & & & & $94 / 241=39 \%$ & & & & \\
\hline
\end{tabular}


Table 5 Grading of body of evidence for the effectiveness of social interventions. Question: Do social interventions result in higher initiation, adherence, or completion rates than usual care in individuals eligible for LTBI treatment? (Continued)

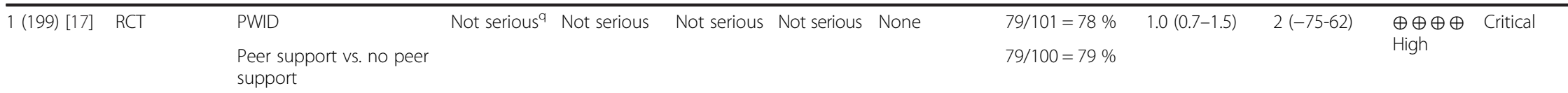

support

$2001[17]$

$\mathrm{n} / \mathrm{N}$ : No of individuals with LTBI who initiated, or adhered to or completed treatment/total number of subjects. Cl: confidence interval; H: isoniazid; OR: odds ratio; RCT: randomized controlled trial

alf $>1$ articles, weighed pooled point estimates and $95 \% \mathrm{Cl}$ were calculated

${ }^{b}$ All groups $\mathrm{H}>4$ months

IIf $>1$ articles, pooled estimates and $95 \% \mathrm{Cl}$ were calculated using a random effects model (without quality index)

${ }^{\mathrm{A} C a l c u l a t e d}$ via GradePro

${ }^{\mathrm{e}}$ Goldberg et al. 2004 [18]: use of unvalidated patient-reported outcomes (self-report); proportion of children aged 5-14 years was higher during one period than the other (19\% vs. $\left.13 \%, p=0.003\right)$

${ }^{f}$ No adherence rates were provided as outcome; instead, the cumulative mean number of pills taken per group was presented

${ }^{9}$ Hovell et al. 2003 [19]: unclear allocation concealment; unclear sequence generation; partly blinded. Not downgraded for these risk of bias aspects because already downgraded for imprecision

${ }^{\text {h}}$ Total sample size $<230$

'Ailinger et al. 2010 [57]: use of unvalidated patient-reported outcomes (self-report) convenience sample

'Hovell et al. 2003 [19]: unclear allocation concealment; unclear sequence generation; partly blinded. Kominski et al. 2007: unclear allocation concealment; no blinding; unclear if intention-to-treat analysis

was performed; use of unvalidated patient-reported outcomes (self-report). Hirsch-Moverman et al. 2013: unclear allocation concealment; unclear sequence generation; partly blinded; use of unvalidated

patient-reported outcomes (self-report)

kInmates who started treatment in jail and were released before treatment completion

'White et al. 2002 [15]: partly blinded

${ }^{\mathrm{m}}$ Total number of events $<125$

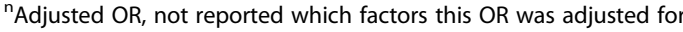

'Nyamathi et al. 2006 [35]: unclear allocation concealment; unclear sequence generation; partly blinded; dissimilarities between treatment arms (daily alcohol or drug use [significantly associated with non-completion in this study]; male, recruitment site [both not significantly associated with completion in this study], lifetime intravenous drug use, recent self-help program)

${ }^{\mathrm{P}}$ Adjusted OR, adjusted for: age, sex, high-school graduate, never married, medical insurance, recruited from homeless shelter, years homeless, treatment completion important, intended to adhere, daily alcohol/drug use, recent self-help program, emotional well-being, social support, recent hospitalization, recent victimization

${ }^{9}$ Chaisson et al. 2001 [17]: unclear allocation concealment; no blinding; use of unvalidated patient-reported outcomes (self-report; urine tests and MEMS in a subset of patients in this study show that

self-report is subject to serious under-reporting) 
Table 6 Grading of body of evidence for effectiveness of other interventions. Question: Do interventions (other than short treatment, incentives or social intervention) result in higher initiation, adherence, or completion rates than usual care in individuals eligible for LTBI treatment?

\begin{tabular}{|c|c|c|c|c|c|c|c|c|c|c|c|c|}
\hline \multirow[b]{2}{*}{$\begin{array}{l}\text { No of studies } \\
\text { (No of participants) }\end{array}$} & \multirow[b]{2}{*}{ Design } & \multirow[b]{2}{*}{$\begin{array}{l}\text { Population } \\
\text { treatment } \\
\text { intervention }\end{array}$} & \multicolumn{5}{|c|}{ Quality assessment } & \multirow{2}{*}{$\begin{array}{l}\mathrm{n} / \mathrm{N}=\% \\
\text { Other intervention } \\
\text { Usual care }\end{array}$} & \multicolumn{2}{|l|}{ Effect } & \multirow[t]{2}{*}{ Quality } & \multirow[t]{2}{*}{ Importance } \\
\hline & & & Risk of bias & Inconsistency & Indirectness & Imprecision & Other considerations & & OR $(95 \% \mathrm{Cl})$ & $\begin{array}{l}\text { Absolute }^{a} \\
\text { (per 1000 } \\
(95 \% \text { Cl)) }\end{array}$ & & \\
\hline \multicolumn{13}{|l|}{ Initiation } \\
\hline \multirow[t]{2}{*}{1 (107) [59] } & $\begin{array}{l}\text { Observational } \\
\text { study }\end{array}$ & $\begin{array}{l}\text { Healthcare } \\
\text { workers H }\end{array}$ & Not serious ${ }^{\mathrm{b}}$ & Not serious & Not serious & Serious $^{c}$ & & $32 / 62=52 \%$ & $8.8(3.1-23)$ & $413(168-631)$ & $\begin{array}{l}\oplus 000 \\
\text { Very low }\end{array}$ & Critical \\
\hline & & Use of IGRAs & & & & & & $5 / 45=11 \%$ & & & & \\
\hline \multicolumn{13}{|l|}{ Adherence } \\
\hline $0(0)$ & $\begin{array}{l}\text { No evidence } \\
\text { available }\end{array}$ & - & - & - & - & - & - & - & - & - & - & Critical \\
\hline \multicolumn{13}{|l|}{ Completion } \\
\hline $0(0)$ & $\begin{array}{l}\text { No evidence } \\
\text { available }\end{array}$ & - & - & - & - & - & - & - & - & - & - & Critical \\
\hline
\end{tabular}

Bibliography: Sahni et al. 2009 [59]

$n / N$ No of individuals with LTBI who initiated, or adhered to or completed treatment/total number of subjects; Cl confidence interval; IGRAs Interferon Gamma Release Assay; OR odds ratio; PWID people who inject drugs; $R C T$ randomised controlled trial

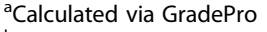

bUse of unvalidated patient-reported outcomes (telephone interview)

'Total number of events $<125$ 


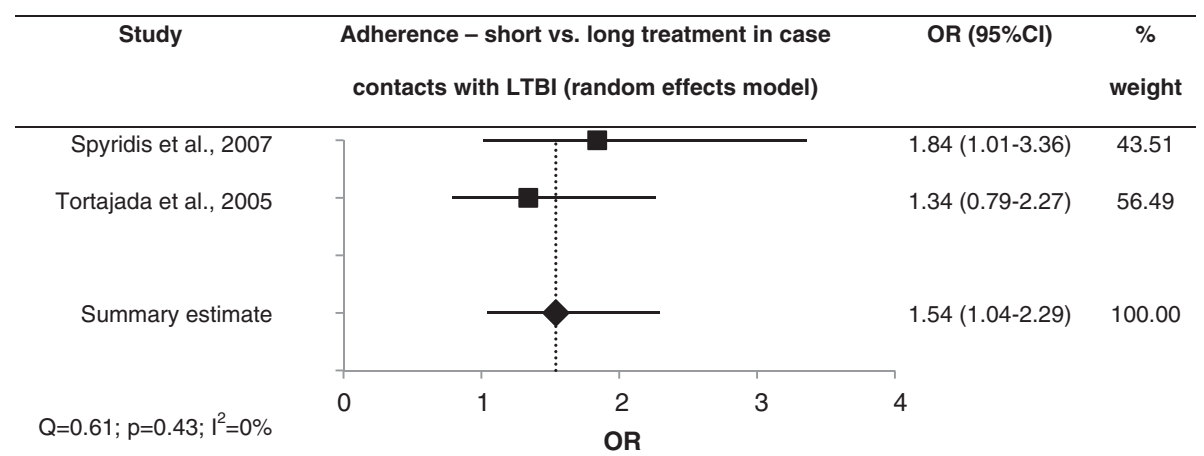

Fig. 1 Forest plot for adherence to short vs. long LTBI treatment in case contacts with LTBI

different measures of associations were used in the studies, the reference groups varied between studies, and data on non-significant factors were not always quantified in the studies and were therefore not listed in this review. However, the same socio-economic factors were also predictors of non-adherence to highly active antiretroviral therapy in human immunodeficiency virus (HIV)-patients or to cardiovascular medication [61-65]. Also, adverse events have been associated with worse adherence to treatment for all these conditions [61, 62]. Similar factors were associated with adherence to treatment for active TB [61].

\section{Interventions}

\section{Initiation}

Some evidence was found that the use of IGRAs rather than TSTs [59], or a social intervention using case management with attention to an individual's cultural background might positively influence the initiation rate of LTBI treatment [18].

\section{Adherence}

Our meta-analysis showed that case contacts had better adherence if they received short treatment compared to those on long treatment regimens $[21,50]$. Social interventions in the form of adherence coaching of adolescents with LTBI and cultural interventions among immigrants with LTBI also resulted in improved adherence $[19,57]$.

\section{Completion}

Overall, completion rates of LTBI treatment were better among groups receiving shorter regimens than those with longer treatment regimens. The only outcome regarding the effect of shorter treatment on completion rates for which no effect was found could be explained by a relatively high rate of hepatotoxicity $(11 \%)$ found in the short treatment arm compared to the long treatment arm (3\%) [21]. This led to premature termination of the study. The applied short regimen of rifampicin plus pyrazinamide is currently not generally offered to persons with LTBI due to its association with hepatotoxicity [66].

Mixed results were found on the effect of DOT on completion rates of LTBI treatment. The significantly lower completion rates among those receiving clinic-based DOT in one study might be attributable to the difficulty undocumented migrants have in reporting regularly to health services to collect their drugs [54]. The study in which no effect was found among PWID did find that more people in the DOT group took all doses and, importantly, also

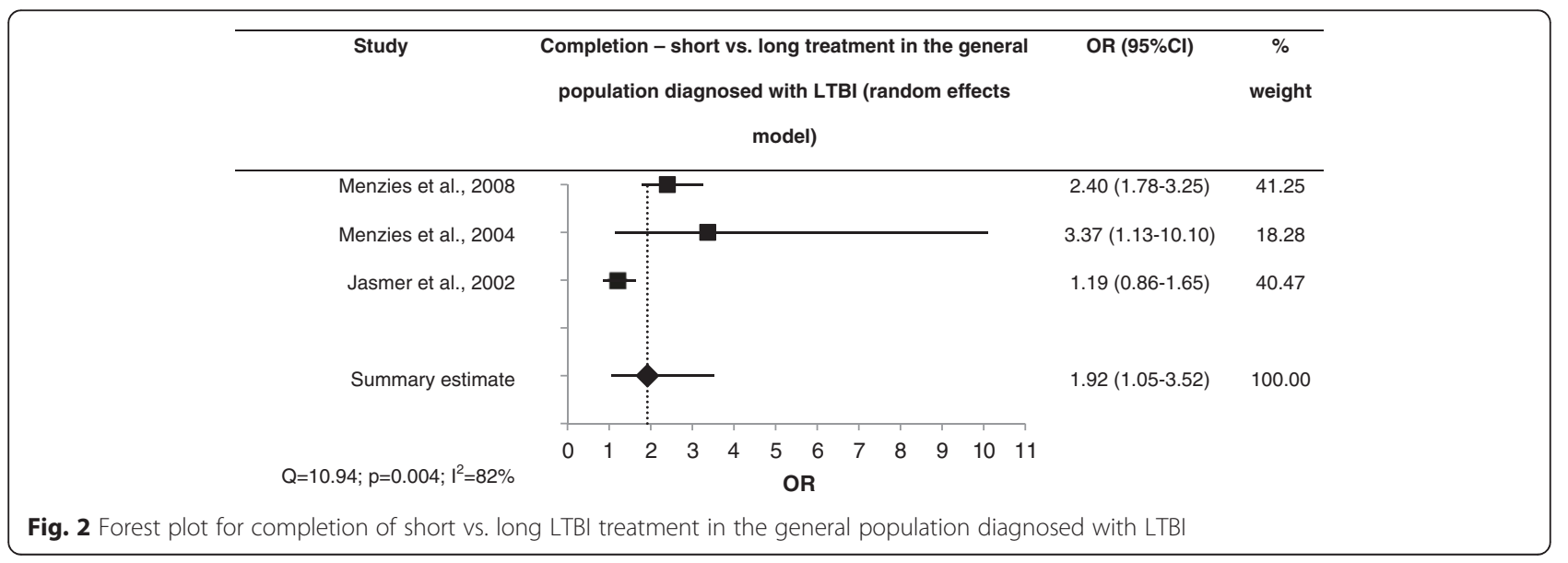




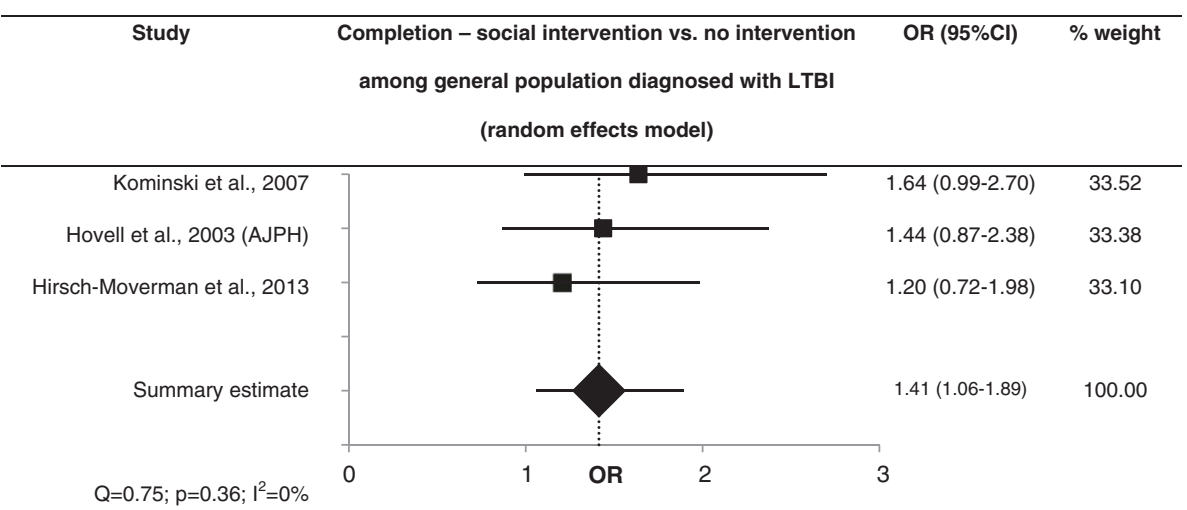

Fig. 3 Forest plot for completion of LTBI treatment using social interventions in the general population diagnosed with LTBI

found that the number of self-reported doses taken was likely to be greatly over-estimated [17]. With regards to two other types of long-term treatment, highly active antiretroviral therapy in HIV-patients and TB treatment, no overall benefit of DOT compared to SAT was found on viral load among HIV-patients or cure among TB patients in reviews by Nachega et al. and Volmink et al. $[67,68]$.

Of the studies reporting on the effect of incentives, two studies conducted in PWID with LTBI found a positive result (one of which was confounded), and the other study in released inmates found no effect. The success of incentives is likely to be both population and setting dependent. Lutge et al. reviewed the literature on material incentives and treatment for latent TB or active TB disease and concluded that the effect on long-term adherence and completion is not clear [69].

Social interventions to improve LTBI treatment uptake included case management with attention for an individual's cultural background, adherence coaching, counselling, contingency contracting, education, nurse case management and peer-based interventions. Most studies on this topic showed better completion rates in the intervention group than in the standard-care group, regardless of the type of social intervention. In a review of RCTs, Schroeder et al. found patient education to be largely unsuccessful in improving adherence to blood pressure-lowering medication, whereas some motivational strategies and complex interventions were successful [70]. In three out of the seven RCTs in a review of Schedlbauer et al. social interventions (i.e. patient information and education, intensified patient care, or a complex behavioral approach) improved adherence rates to lipid-lowering medication) [71].

\section{Other reviews}

Several other reviews present data on interventions to improve medication uptake among LTBI patients. These reviews had specific questions, for example the effect of lay healthcare workers on completion of LTBI treatment [72], interventions to improve the health of the homeless [73], education or counselling to improve completion of LTBI treatment [7], effects of rifampicin monotherapy or rifamycin-combination therapy versus isoniazid for preventing active $\mathrm{TB}$ and the role of completion rates [9]; incentives to reinforce medication adherence, including for LTBI treatment [10, 69]. However, these reviews included only a small number of studies with the specific aim to investigate interventions to improve LTBI treatment initiation, adherence or completion. Some of these articles were also included in the current review; some could not be included in our review because we used different inclusion criteria.

\section{Limitations}

The definitions of completion varied between the included studies, as did the ways in which treatment adherence was assessed and in which completion rates were calculated. For example definitions used varied from "completed four months of rifampicin" to "picked up nine months of isoniazid within twelve months" and "took at least $80 \%$ of the prescribed medication within twenty weeks". This heterogeneity complicates comparison of rates between studies and hampers meta-analysis and interpretation of the results. Since adherence and completion are similar concepts in the sense that full adherence to a treatment regimen leads to its completion, the limitations that are applicable to measures for completion are also applicable to adherence.

There is no standard definition for LTBI using tuberculin reactivity which is universally accepted.

There were no pre-set LTBI diagnostic criteria for inclusion of the studies in this review, the inclusion relied on reporting of the diagnostic criteria of the individual studies; if the study considered a case to be diagnosed then the study was included in the review and those cases were analysed.

Only determinants that showed a statistically significant association with initiation, adherence and completion were listed in this article, this should be taken into account when interpreting the results. The power of a study to 
detect a significant effect was not taken into account in this review. Additionally, the determinants were merely described and no summary analyses were done because the non-significant determinants were not quantified and because of heterogeneity between the included studies. Comparison of studies is also complicated by the fact that different measures of association were used by the included studies; reference groups may differ; or the definition of the determinant itself might vary. These intricacies would be lost when grouping the determinants.

We calculated summary estimates for studies with similar populations and interventions. However, the studies were still quite heterogeneous. Calculation of summary estimates by combining studies without correcting for possible bias-causing factors between studies may cause bias in the results. Furthermore, the $\mathrm{I}^{2}$ estimates need to be interpreted with caution because each meta-analysis only included three studies.

Finally, when conducting a systematic review, any limitations of included studies (e.g. lack of controlling for relevant covariates) inherently become limitations of data presented in the review.

\section{Gaps and future research}

The number of intervention studies in specific populations was scarce. In order to generate evidence on the effectiveness of context-specific interventions to improve the uptake of LTBI treatment, RCTs tailored to specific populations, with consideration of available resources and infrastructure of the health system, are necessary [11]. Although clinically relevant, no determinants of initiation, adherence or completion were found for patients with comorbidities.

Ultimately, the effect of LTBI treatment on the development of TB disease is important, and initiation, adherence and completion rates of LTBI treatment are intermediate determinants. In a subgroup analysis of a network meta-analysis of RCTs to determine the most efficacious regimen for preventing active TB disease [74], no evidence of a relationship between adherence (expressed as overall percentage of doses received) and efficacy was found. Still, more information on the association between treatment adherence and efficacy for prevention of active TB may be valuable.

\section{Conclusions}

Clinical benefit to individuals with LTBI and the success of the LTBI control programme in general are dependent on individuals taking the medication and completing the full course of treatment [11]. In the first part of this review, it was found that initiation and completion rates of LTBI treatment were frequently suboptimal and varied greatly within and across different populations. Taking determinants of initiation, adherence, and completion into account is an important first to step to plan interventions to improve these rates.

The available evidence on the effect of interventions on treatment initiation, adherence and completion presented in this review suggests that some interventions, notably the use of shorter treatment regimens and social interventions, have a positive effect on adherence and completion.

Overall, however, the evidence was inconclusive and recommendations on the best interventions to improve uptake of LTBI medication are hampered by the heterogeneity of the studies. The benefit of interventions to improve treatment completion, such as incentives and DOT, appears to be population and setting dependent. Specific needs of the different populations with LTBI should be addressed taking into consideration the local context, specific settings and conditions in which the LTBI treatment programme is implemented.

\section{Ethics approval and consent to participate}

Not applicable.

\section{Consent for publication}

Not applicable.

\section{Availability of data and materials}

The datasets supporting the conclusions of this article are included within the article and its additional files.

\section{Additional files}

\section{Additional file 1: Materials and methods. (DOCX $47 \mathrm{~kb}$ ) \\ Additional file 2: Flow chart of selection process. (DOCX $257 \mathrm{~kb}$ ) \\ Additional file 3: Study characteristics, outcomes, and quality aspects of risk of bias assessment of articles on determinants of initiation, adherence and completion of LTBI treatment regimens. (DOCX $151 \mathrm{~kb}$ ) \\ Additional file 4: Study characteristics, outcomes, and risk of bias assessment of articles on interventions to improve initiation, adherence and completion of LTBI treatment regimens. (DOCX $104 \mathrm{~kb}$ )}

\begin{abstract}
Abbreviations
DOT: directly observed therapy; EU/EEA: European Union and European Economic Area; GRADE: Grading of Recommendations Assessment, Development and Evaluation; HIV: human immunodeficiency virus; IGRAs: interferon gamma release assay; LTBI: latent tuberculosis infection; ORs: odds ratios; PWID: people who injected drugs; RCT: randomized controlled trial; SAT: self-administered therapy; TB: tuberculosis; TST: tuberculin skin tests; WHO: World Health Organization.
\end{abstract}

\section{Competing interests}

The authors declare that they have no competing interests.

\section{Authors' contributions}

MVN, AS and MvdW designed the review and search strategy. FVK and ALS searched the literature, selected the studies, extracted, graded and analyzed data. MVN and AO controlled the quality of the review process. MVN, AO and MvdW assessed the quality of data analysis. ALS, AO, MVN and AS drafted the manuscript. MVN, AO, FVK, ALS, AS and MvdW edited the manuscript. All authors read and approved the final manuscript. 


\section{Acknowledgements}

Not applicable.

\section{Funding}

This work was performed under the ECDC Framework Contract FWC/ECDC/2013/ 005 Specific Contract No. 1 ECD.4065 awarded to the consortium consisting of Pallas, health research and consultancy and the Department of Public Health, Erasmus MC, and Service contract ECD.5000 of OJ/02/05/2014-PROC/2014/015 awarded to Pallas, health research and consultancy.

\section{Author details}

'Pallas health research and consultancy BV, Rotterdam, The Netherlands.

EEuropean Centre for Disease Prevention and Control (ECDC),

Tomtebodavägen 11a, Solna 171 65, Sweden.

\section{Received: 13 February 2016 Accepted: 7 May 2016}

\section{Published online: 08 June 2016}

\section{References}

1. Lillebaek T, Dirksen A, Baess I, Strunge B, Thomsen VO, Andersen AB. Molecular evidence of endogenous reactivation of Mycobacterium tuberculosis after 33 years of latent infection. J Infect Dis. 2002;185:401-4

2. Barry 3rd CE, Boshoff HI, Dartois $V$, et al. The spectrum of latent tuberculosis: rethinking the biology and intervention strategies. Nat Rev Microbiol. 2009; 7:845-55.

3. Dye C, Scheele S, Dolin P, Pathania V, Raviglione MC. Consensus statement. Global burden of tuberculosis: estimated incidence, prevalence, and mortality by country. WHO Global Surveillance and Monitoring Project. JAMA. 1999;282: 677-86.

4. World Health Organization. The END TB strategy - Global strategy and targets for tuberculosis prevention, care and control after 2015. In: Geneva: WHO, ed, 2014:2.

5. World Health Organization. Draft global strategy and targets for tuberculosis prevention, care and control after 2015. In: Secretariat, editor. World Health Assembly. Geneva: WHO; 2014.

6. Adams LV, Talbot EA, Odato K, Blunt H, Steingart KR. Interventions to improve delivery of isoniazid preventive therapy: an overview of systematic reviews. BMC Infect Dis. 2014;14:281.

7. M'Imunya JM, Kredo T, Volmink J. Patient education and counselling for promoting adherence to treatment for tuberculosis. Cochrane Database Syst Rev. 2012;5:CD006591.

8. Osterberg L, Blaschke T. Adherence to medication. N Engl J Med. 2005;353: 487-97.

9. Sharma SK, Sharma A, Kadhiravan T, Tharyan P. Rifamycins (rifampicin, rifabutin and rifapentine) compared to isoniazid for preventing tuberculosis in HIV-negative people at risk of active TB. Cochrane Database Syst Rev. 2013;7:CD007545.

10. DeFulio A, Silverman $\mathrm{K}$. The use of incentives to reinforce medication adherence. Prev Med. 2012;55(Suppl):S86-94.

11. World Health Organization. Guidelines on the management of latent tuberculosis infection. The End TB Strategy: WHO; 2015.

12. Guyatt $\mathrm{GH}$, Oxman $A D$, Kunz R, et al. GRADE guidelines 6. Rating the quality of evidence-imprecision. J Clin Epidemiol. 2011;64:1283-93.

13. Cochrane Informatics \& Knowledge Management Department. GRADEpro. Available at: https://tech.cochrane.org/revman/other-resources/gradepro/ download. Accessed April 292014.

14. Neyeloff $J$, Fuchs SC, Moreira LB. Meta-analyses and Forest plots using a microsoft excel spreadsheet: step-by-step guide focusing on descriptive data analysis. BMC Res Notes. 2012;5:52.

15. White MC, Tulsky JP, Goldenson J, Portillo CJ, Kawamura M, Menendez E. Randomized controlled trial of interventions to improve follow-up for latent tuberculosis infection after release from jail. Arch Intern Med. 2002;162:1044-50.

16. Batki SL, Gruber VA, Bradley JM, Bradley M, Delucchi K. A controlled trial of methadone treatment combined with directly observed isoniazid for tuberculosis prevention in injection drug users. Drug Alcohol Depend. 2002;66:283-93.

17. Chaisson RE, Barnes GL, Hackman J, et al. A randomized, controlled trial of interventions to improve adherence to isoniazid therapy to prevent tuberculosis in injection drug users. Am J Med. 2001;110:610-5.

18. Goldberg SV, Wallace J, Jackson JC, Chaulk CP, Nolan CM. Cultural case management of latent tuberculosis infection. Int J Tuberc Lung Dis. 2004;8:76-82.
19. Hovell MF, Sipan CL, Blumberg EJ, et al. Increasing Latino adolescents' adherence to treatment for latent tuberculosis infection: a controlled trial. Am J Public Health. 2003;93:1871-7.

20. Sterling TR, Villarino ME, Borisov AS, et al. Three months of rifapentine and isoniazid for latent tuberculosis infection. N Engl J Med. 2011;365:2155-66.

21. Tortajada C, Martinez-Lacasa J, Sanchez F, et al. Is the combination of pyrazinamide plus rifampicin safe for treating latent tuberculosis infection in persons not infected by the human immunodeficiency virus? Int J Tuberc Lung Dis. 2005;9:276-81.

22. Gershon AS, McGeer A, Bayoumi AM, Raboud J, Yang J. Health care workers and the initiation of treatment for latent tuberculosis infection. Clin Infect Dis. 2004;39:667-72.

23. Horsburgh Jr CR, Goldberg S, Bethel J, et al. Latent TB infection treatment acceptance and completion in the United States and Canada. Chest. 2010; 137:401-9.

24. Goswami ND, Gadkowski LB, Piedrahita C, et al. Predictors of latent tuberculosis treatment initiation and completion at a U.S. public health clinic: a prospective cohort study. BMC Public Health. 2012;12:468.

25. Morano JP, Walton MR, Zelenev A, Bruce RD, Altice FL. Latent tuberculosis infection: screening and treatment in an urban setting. J Community Health. 2013:38:941-50.

26. Nuzzo JB, Golub JE, Chaulk P, Shah M. Analysis of latent tuberculosis infection treatment adherence among refugees and other patient groups referred to the Baltimore City Health Department TB Clinic, February 2009-March 2011. J Immigr Minor Health. 2013;17(1):56-65.

27. Kominski GF, Varon SF, Morisky DE, et al. Costs and cost-effectiveness of adolescent compliance with treatment for latent tuberculosis infection: results from a randomized trial. J Adolesc Health. 2007:40:61-8.

28. Chang AH, Polesky A, Bhatia G. House calls by community health workers and public health nurses to improve adherence to isoniazid monotherapy for latent tuberculosis infection: a retrospective study. BMC Public Health. 2013;13:894.

29. Haley CA, Stephan S, Vossel LF, Sherfy EA, Laserson KF, Kainer MA. Successful use of rifampicin for Hispanic foreign-born patients with latent tuberculosis infection. Int J Tuberc Lung Dis. 2008;12:160-7.

30. LoBue PA, Moser KS. Use of isoniazid for latent tuberculosis infection in a public health clinic. Am J Respir Crit Care Med. 2003;168:443-7.

31. Li J, Munsiff SS, Tarantino T, Dorsinville M. Adherence to treatment of latent tuberculosis infection in a clinical population in New York City. Int J Infect Dis. 2010;14:e292-7.

32. Hirsch-Moverman Y, Bethel J, Colson PW, Franks J, El-Sadr W. Predictors of latent tuberculosis infection treatment completion in the United States: an inner city experience. Int J Tuberc Lung Dis. 2010;14:1104-11.

33. Codecasa LR, Murgia N, Ferrarese $M$, et al. Isoniazid preventive treatment: predictors of adverse events and treatment completion. Int J Tuberc Lung Dis. 2013;17:903-8

34. Lee AM, Mennone JZ, Jones RC, Paul WS. Risk factors for hepatotoxicity associated with rifampin and pyrazinamide for the treatment of latent tuberculosis infection: experience from three public health tuberculosis clinics. Int J Tuberc Lung Dis. 2002;6:995-1000.

35. Nyamathi AM, Christiani A, Nahid P, Gregerson P, Leake B. A randomized controlled trial of two treatment programs for homeless adults with latent tuberculosis infection. Int J Tuberc Lung Dis. 2006:10:775-82.

36. Anibarro L, Casas S, Paz-Esquete J, et al. Treatment completion in latent tuberculosis infection at specialist tuberculosis units in Spain. Int J Tuberc Lung Dis. 2010;14:701-7.

37. Lobato MN, Reves RR, Jasmer RM, Grabau JC, Bock NN, Shang N. Adverse events and treatment completion for latent tuberculosis in jail inmates and homeless persons. Chest. 2005;127:1296-303.

38. Jimenez-Fuentes MA, de Souza-Galvao ML, Mila Auge C, Solsona Peiro J, AltetGomez MN. Rifampicin plus isoniazid for the prevention of tuberculosis in an immigrant population. Int J Tuberc Lung Dis. 2013;17:326-32.

39. Fresard I, Bridevaux PO, Rochat T, Janssens JP. Adverse effects and adherence to treatment of rifampicin 4 months vs isoniazid 6 months for latent tuberculosis: a retrospective analysis. Swiss Med Wkly. 2011;141:W13240.

40. Lardizabal A, Passannante M, Kojakali F, Hayden C, Reichman LB. Enhancement of treatment completion for latent tuberculosis infection with 4 months of rifampin. Chest. 2006;130:1712-7.

41. Page KR, Sifakis F, Montes de Oca R, et al. Improved adherence and less toxicity with rifampin vs isoniazid for treatment of latent tuberculosis: a retrospective study. Arch Intern Med. 2006;166:1863-70. 
42. Young $H$, Wessolossky M, Ellis J, Kaminski M, Daly JS. A retrospective evaluation of completion rates, total cost, and adverse effects for treatment of latent tuberculosis infection in a public health clinic in central massachusetts. Clin Infect Dis. 2009:49:424-7.

43. Bastos ML, Menzies D, Belo MT, et al. Changes in QuantiFERON(R)-TB Gold In-Tube results during treatment for tuberculous infection. Int J Tuberc Lung Dis. 2013;17:909-16.

44. White MC, Gournis E, Kawamura M, Menendez E, Tulsky JP. Effect of directly observed preventive therapy for latent tuberculosis infection in San Francisco. Int J Tuberc Lung Dis. 2003;7:30-5.

45. Cruz AT, Starke JR. Increasing adherence for latent tuberculosis infection therapy with health department-administered therapy. Pediatr Infect Dis J. 2012;31:193-5.

46. Chang SH, Eitzman SR, Nahid P, Finelli ML. Factors associated with failure to complete isoniazid therapy for latent tuberculosis infection in children and adolescents. J Infect Public Health. 2014;7:145-52.

47. Kwara A, Herold JS, Machan JT, Carter EJ. Factors associated with failure to complete isoniazid treatment for latent tuberculosis infection in Rhode Island. Chest. 2008;133:862-8

48. Vinnard C, Gopal A, Linkin DR, Maslow J. Isoniazid Toxicity among an Older Veteran Population: A Retrospective Cohort Study. Tuberc Res Treat. 2013; 2013:549473.

49. Gilroy SA, Rogers MA, Blair DC. Treatment of latent tuberculosis infection in patients aged $>$ or $=35$ years. Clin Infect Dis. 2000;31:826-9.

50. Spyridis NP, Spyridis PG, Gelesme A, et al. The effectiveness of a 9-month regimen of isoniazid alone versus 3 - and 4-month regimens of isoniazid plus rifampin for treatment of latent tuberculosis infection in children: results of an 11-year randomized study. Clin Infect Dis. 2007;45:715-22.

51. Jasmer RM, Saukkonen JJ, Blumberg HM, et al. Short-course rifampin and pyrazinamide compared with isoniazid for latent tuberculosis infection: a multicenter clinical trial. Ann Intern Med. 2002;137:640-7.

52. Menzies D, Dion MJ, Rabinovitch B, Mannix S, Brassard P, Schwartzman K. Treatment completion and costs of a randomized trial of rifampin for 4 months versus isoniazid for 9 months. Am J Respir Crit Care Med. 2004;170:445-9.

53. Menzies D, Long R, Trajman A, et al. Adverse events with 4 months of rifampin therapy or 9 months of isoniazid therapy for latent tuberculosis infection: a randomized trial. Ann Intern Med. 2008;149:689-97.

54. Matteelli A, Casalini C, Raviglione MC, et al. Supervised preventive therapy for latent tuberculosis infection in illegal immigrants in Italy. Am J Respir Crit Care Med. 2000;162:1653-5.

55. Malotte CK, Hollingshead JR, Larro M. Incentives vs outreach workers for latent tuberculosis treatment in drug users. Am J Prev Med. 2001;20:103-7.

56. Tulsky JP, Hahn JA, Long HL, et al. Can the poor adhere? Incentives for adherence to TB prevention in homeless adults. Int J Tuberc Lung Dis. 2004:8:83-91.

57. Ailinger RL, Martyn D, Lasus H, Lima GN. The effect of a cultural intervention on adherence to latent tuberculosis infection therapy in Latino immigrants. Public Health Nurs. 2010;27:115-20.

58. Hirsch-Moverman Y, Colson PW, Bethel J, Franks J, El-Sadr WM. Can a peer-based intervention impact adherence to the treatment of latent tuberculous infection? Int J Tuberc Lung Dis. 2013;17:1178-85.

59. Sahni R, Miranda C, Yen-Lieberman B, et al. Does the implementation of an interferon-gamma release assay in lieu of a tuberculin skin test increase acceptance of preventive therapy for latent tuberculosis among healthcare workers? Infect Control Hosp Epidemiol. 2009;30:197-9.

60. Cass AD, Talavera GA, Gresham LS, Moser KS, Joy W. Structured behavioral intervention to increase children's adherence to treatment for latent tuberculosis infection. Int J Tuberc Lung Dis. 2005;9:415-20.

61. Sabaté E e. Adherence to long-term therapies: evidence for action. In: Sabaté E, ed. Geneva: World Health Organization; 2003.

62. Bowry AD, Shrank WH, Lee $J$, Stedman M, Choudhry NK. A systematic review of adherence to cardiovascular medications in resource-limited settings. J Gen Intern Med. 2011;26:1479-91.

63. Lemstra M, Blackburn D, Crawley A, Fung R. Proportion and risk indicators of nonadherence to statin therapy: a meta-analysis. CanJ Cardiol. 2012;28:574-80.

64. Malta M, Magnanini MM, Strathdee SA, Bastos FI. Adherence to antiretroviral therapy among HIV-infected drug users: a meta-analysis. AIDS Behav. 2010; 14:731-47.

65. Lemstra M, Alsabbagh MW. Proportion and risk indicators of nonadherence to antihypertensive therapy: a meta-analysis. Patient Preference Adherence. $2014 ; 8: 211-8$
66. Centers for Disease Control and Prevention, American Thoracic Society. Update: adverse event data and revised American Thoracic Society/CDC recommendations against the use of rifampin and pyrazinamide for treatment of latent tuberculosis infection-United States, 2003. MMWR Morb Mortal Wkly Rep. 2003; 52:735-9.

67. Ford N, Nachega JB, Engel ME, Mills EJ. Directly observed antiretroviral therapy: a systematic review and meta-analysis of randomised clinical trials. Lancet. 2009;374:2064-71.

68. Volmink J, Garner P. Directly observed therapy for treating tuberculosis. Cochrane Database Syst Rev. 2007;(4):Cd003343.

69. Lutge EE, Wiysonge CS, Knight SE, Volmink J. Material incentives and enablers in the management of tuberculosis. Cochrane Database Syst Rev. 2012;1: CD007952.

70. Schroeder K, Fahey T, Ebrahim S. How can we improve adherence to blood pressure-lowering medication in ambulatory care? Systematic review of randomized controlled trials. Arch Intern Med. 2004;164:722-32.

71. Schedlbauer A, Schroeder K, Fahey T. How can adherence to lipid-lowering medication be improved? A systematic review of randomized controlled trials. Fam Pract. 2007;24:380-7.

72. Lewin S, Munabi-Babigumira S, Glenton C, et al. Lay health workers in primary and community health care for maternal and child health and the management of infectious diseases. Cochrane Database Syst Rev. 2010;CD004015.

73. Hwang SW, Tolomiczenko G, Kouyoumdjian FG, Garner RE. Interventions to improve the health of the homeless: a systematic review. Am J Prev Med. 2005;29:311-9.

74. Stagg HR, Zenner D, Harris RJ, Munoz L, Lipman MC, Abubakar I. Treatment of latent tuberculosis infection: a network meta-analysis. Ann Intern Med. 2014;161:419-28.

75. Hovell M, Blumberg E, Gil-Trejo L, et al. Predictors of adherence to treatment for latent tuberculosis infection in high-risk Latino adolescents: a behavioral epidemiological analysis. Soc Sci Med. 2003;56:1789-96.

76. Berg J, Blumberg EJ, Sipan CL, et al. Somatic complaints and isoniazid (INH) side effects in Latino adolescents with latent tuberculosis infection (LTBI). Patient Educ Couns. 2004;52:31-9.

77. Fountain FF, Tolley E, Chrisman CR, Self TH. Isoniazid hepatotoxicity associated with treatment of latent tuberculosis infection: A 7-year evaluation from a public health tuberculosis clinic. Chest. 2005;128:116-23.

78. Morisky DE, Ebin VJ, Malotte CK, Coly A, Kominski G. Assessment of tuberculosis treatment completion in an ethnically diverse population using two data sources. Implications for treatment interventions. Eval Health Prof. 2003;26:43-58.

79. Rennie TW, Bothamley GH, Engova D, Bates IP. Patient choice promotes adherence in preventive treatment for latent tuberculosis. Eur Respir J. 2007;30:728-35

80. Parsyan AE, Saukkonen J, Barry MA, Sharnprapai S, Horsburgh Jr CR. Predictors of failure to complete treatment for latent tuberculosis infection. J Infect. 2007; 54:262-6.

81. McElroy PD, ljaz K, Lambert LA, et al. National survey to measure rates of liver injury, hospitalization, and death associated with rifampin and pyrazinamide for latent tuberculosis infection. Clin Infect Dis. 2005;41:1125-33.

82. Kan B, Kalin M, Bruchfeld J. Completing treatment for latent tuberculosis: patient background matters. Int J Tuberc Lung Dis. 2013;17:597-602.

83. Shieh FK, Snyder G, Horsburgh CR, Bernardo J, Murphy C, Saukkonen JJ. Predicting non-completion of treatment for latent tuberculous infection: a prospective survey. Am J Respir Crit Care Med. 2006;174:717-21. 